\title{
Balloon dilatation of the external urethral sphincter in the treatment of detrusor-sphincter dyssynergia
}

\author{
JP McFarlane, SJ Foley and PJR Shah \\ Spinal Injuries Unit, Royal National Orthopaedic Hospital, Stanmore, Middlesex, UK
}

\begin{abstract}
Balloon dilatation of the external urethral sphincter was introduced in our unit in 1990 as an alternative to sphincterotomy in the surgical management of detrusor-sphincter dyssynergia in spinally injured patients. The initial results with the technique looked promising. We performed 14 balloon dilatations in the period 1990-1993, and these patients have been followed up for $8-68$ months (mean 55.5). The procedure was effective in relieving symptoms and had a low morbidity. Sphincter activity assessed at cystoscopy was initially abolished in all patients. Vesicoureteric reflux present in one patient pre-operatively resolved after the procedure. However the long-term results are disappointing, with an $85 \%$ failure rate $(62 \%$ within 1 year). Balloon dilatation in our series has a lower success rate than both sphincterotomy and sphincter stenting and cannot be recommended for the treatment of detrusor-sphincter dyssynergia.
\end{abstract}

Keywords: spinal cord injury; detrusor-sphincter dyssynergia; balloon dilatation; sphincterotomy

\section{Introduction}

Spinally injured patients with the combination of hyperreflexia and detrusor-sphincter dyssynergia suffer the highest incidence of urological complications. ${ }^{1-3}$ This is believed to be caused by the combination of prolonged elevations of intravesical pressure and incomplete bladder emptying seen in this group. For over 30 years, sphincterotomy has been the standard operation to lower outflow tract resistance and thus reduce intravesical pressures. However, the procedure sometimes produces poor results and some patients require multiple repeat operations. A variety of techniques have been introduced in the last decade to try and improve this. Balloon dilatation was first introduced as an alternative to transurethral prostatectomy in the treatment of benign prostatic hypertrophy. Balloon dilatation of the external sphincter was first used in our unit in 1990 as an alternative to sphincterotomy. Initial results with the technique suggested it was effective, ${ }^{4,5}$ but no long-term results have been published.

\section{Methods}

Fourteen balloon dilatations were performed on 13 patients in the period 1990-1993. All patients had detrusor-sphincter dyssynergia (DSD) and sustained high intravesical pressures on pre-operative urodynamic assessment. In addition, one patient had vesicoureteric reflux, three had recurrent urinary tract

Correspondence: JP McFarlane infections and six suffered from autonomic dysreflexia. The procedure was performed under general anaesthesia with the Optilume prostate dilatation system (American Medical Systems, Minnesota, USA) and endoscopic guidance. The balloon was placed across the external urethral sphincter and inflated to a pressure of three atmospheres for a period of $10 \mathrm{~min}$. The balloon was then deflated and the sphincter assessed via the cystoscope.

Patients were followed up for between 8 and 68 months (mean 55.5, median 61) with regular videourodynamic and ultrasonic assessment. Twelve patients had urodynamics immediately before the operation and within 6 months after the procedure. The urodynamic data from these patients were analyzed for statistical significance using a paired $t$-test.

\section{Results}

Loss of sphincter activity and splitting of the mucosa overlying the sphincter was seen through the cystoscope immediately after all 14 procedures. One patient developed septicaemia post-operatively but made a full recovery. Haemorrhage following the procedure was common but always settled without the need for transfusion. Six patients suffered from autonomic dysreflexia pre-operatively and all noticed improvement in their symptoms following balloon dilatation after the procedure. Vesicoureteric reflux noted in one patient prior to operation also resolved. No adverse effects on sexual function were found. Full pre- and post-operative urodynamic data was available in 12 
patients (Table 1). There were no statistically significant changes in any urodynamic parameters, although there was a decrease in maximum detrusor pressure which approached significance.

A successful long-term outcome was regarded as resolution of symptoms, satisfactory urodynamic parameters, absence of DSD on videourodynamics and avoidance of upper tract complications. Failure was defined as recurrence of DSD or symptoms, sustained high pressure detrusor contractions, high residual urine measurements or upper tract complications. Eleven of the 13 patients failed during the follow-up period (Table 2), eight of them within 12 months. One late failure after 32 months had a repeat balloon dilatation and has subsequently had a successful outcome up to 70 months follow-up. One patient has recurrent DSD demonstrated on videourodynamics, but has satisfactory urodynamic parameters and thus has avoided any further intervention. A further patient developed recurrent autonomic dysreflexia after 8 months but was subsequently lost to follow-up. The remaining eight patients have all required further surgical intervention. Two patients had a successful outcome and remain on condom drainage having avoided further intervention.

Table 1 Pre- and post-operative urodynamic data (mean \pm 1 standard deviation)

\begin{tabular}{lccc}
\hline $\begin{array}{l}\text { Urodynamic } \\
\text { parameter }\end{array}$ & $\begin{array}{c}\text { Pre- } \\
\text { operative }\end{array}$ & $\begin{array}{c}\text { Post- } \\
\text { operative }\end{array}$ & P-value \\
\hline $\left.\begin{array}{c}\text { Maximum detrusor } \\
\text { pressure (cmH }\end{array} \mathrm{c}_{2} \mathrm{O}\right)$ & $95 \pm 41$ & $74 \pm 35$ & 0.06 \\
$\begin{array}{c}\text { Average duration of } \\
\text { contraction (s) }\end{array}$ & $160 \pm 122$ & $154 \pm 108$ & 0.40 \\
$\begin{array}{c}\text { Residual urine } \\
\text { volume (ml) }\end{array}$ & $213 \pm 202$ & $220 \pm 219$ & 0.26 \\
$\begin{array}{c}\text { Cystometric capacity } \\
(\mathrm{ml})\end{array}$ & $358 \pm 180$ & $430 \pm 249$ & 0.16 \\
\hline
\end{tabular}

\section{Discussion}

Sphincterotomy is the principal procedure used to lower outflow tract resistance and facilitate low pressure voiding into a condom drainage system, but has several problems. The operation is destructive (often a major consideration for spinally injured patients), frequently causes profuse haemorrhage and may cause erectile dysfunction. Recent studies of the long-term efficacy of sphincterotomy have also shown a high incidence of complications and reoperation. ${ }^{6,7}$ For these reasons there has been an interest in other techniques to inactivate the sphincter, such as balloon dilatation, stenting and botulinum toxin injection.

Balloon dilatation has largely proved to be an ineffective treatment for benign prostatic hyperplasia as any beneficial effects seem to be of short duration. One randomised double blind study showed no difference between balloon dilatation of the prostate and cystoscopy at 3 months. ${ }^{8}$ However, the external urethral sphincter is both smaller and less elastic than the prostate and thus might be expected to be damaged more by stretching. Chancellor et al reported a successful outcome in 14 out of $17(82 \%)$ patients with DSD treated with balloon dilatation under fluoroscopic control followed for between 3 and 20 months, as assessed by videourodynamic and cystoscopic investigation. In comparison, our results show a $62 \%$ failure rate at 1 year, with an $85 \%$ longterm failure rate. The high failure rate was principally caused by a return of sphincteric function, producing either symptoms such as autonomic dysreflexia and recurrent infections, or a deterioration in urodynamic parameters which warranted further surgical intervention. The re-operation rate in this series was $69.2 \%$, with most of the procedures needed within a year of the initial balloon dilatation. This compares to a reoperation rate of $15-50 \%$ for sphincterotomy patients. $^{6,9,10}$ Recently, laser sphincterotomy has been introduced, and seems to cause less bleeding and have a lower re-operation rate than conventional sphincter-

Table 2 Patient outcome following balloon dilatation

\begin{tabular}{lccc}
\hline $\begin{array}{l}\text { Follow-up duration } \\
\text { (months) }\end{array}$ & $\begin{array}{c}\text { Time to failure } \\
\text { (months) }\end{array}$ & Reason for failure & Subsequent management \\
\hline 64 & 4 & DSD, high intravesical pressures & Sphincterotomy \\
61 & 4 & DSD, high intravesical pressure & Sphincterotomy \\
56 & 5 & High residual urine, DSD & Sphincterotomy \\
8 & 8 & Autonomic dysreflexia & Lost to follow-up \\
62 & 8 & High residual urine, autonomic dysreflexia & Sphincterotomy, sphincter stent \\
68 & 10 & High intravesical pressure, residual urine & Suprapubic catheter \\
57 & 11 & DSD, high intravesical pressure & Sphincterotomy, sphincter stent \\
47 & 12 & High residual urine, DSD & Sphincterotomy \\
68 & 32 & DSD, hydronephrosis & Sphincter stent \\
62 & 32 & DSD, vesicoureteric reflux & Repeat balloon dilatation \\
54 & 38 & DSD & No treatment required \\
50 & - & Successful outcome & - \\
65 & - & Successful outcome & - \\
\hline
\end{tabular}


otomy whilst having similar efficacy. ${ }^{11,12}$ Several reports of the short-term results of sphincter stenting have confirmed that the procedure is straightforward with a low incidence of immediate complications. ${ }^{13-16}$ Stenting appears to be as effective as sphincterotomy in relieving symptoms and improving urodynamic parameters.

Two of our thirteen patients developed upper tract complications $(15.4 \%)$, which is less than the figure quoted for long-term follow-up of sphincterotomy $(30 \%),{ }^{7}$ but the majority of our patients have undergone further procedures to lower their intravesical pressure. We believe the low rate of upper tract changes is due to our policy of aggressive surgical management of high intravesical pressure rather than the choice of outflow tract operation.

Although balloon dilatation of the external urethral sphincter is a less complex procedure than sphincterotomy, it is an ineffective long-term treatment for detrusor-sphincter dyssynergia in the majority of patients. Sphincterotomy and external urethral sphincter stenting should be the surgical treatments of choice for this condition.

\section{References}

1 Hackler RH. A 25 year prospective mortality study on the spinal cord injured patient: comparison with the long-term living paraplegic. J Urol 1977; 117: 486-488.

2 Borges P, Hackler RH. The urologic status of the Vietnam war paraplegic: a 15 year prospective follow-up. J Urol 1984; 127: $710-711$.

3 Blavais JG, Sinha HP, Zayed AAH, Labib KB.. Detrusorexternal sphincter dyssynergia. J Urol 1981; 125: $542-544$
4 Chancellor MB et al. Transurethral balloon dilatation of the external urinary sphincter: effectiveness in spinal cord injured men with detrusor-external urethral sphincter dyssynergia. Radiology 1993; 187: $557-560$.

5 Chancellor MB et al. Prospective comparison of external sphincter balloon dilatation and prosthesis placement with external sphincterotomy in spinal cord injured men. Arch Phys Med Rehabil 1994; 75: $297-305$.

6 Vapnek JM, Couillard DR, Stone AR. Is sphincterotomy the best management of the spinal cord injured bladder? J Urol 1994; 151: $961-964$.

7 Juma S, Mostafavi M, Joseph A. Sphincterotomy: long-term complications and warning signs. Neurourol Urodynam 1995; 14: $33-41$.

8 Lepor H, Sypherd D, Machi G, Derus J. Randomized doubleblind study comparing the effectiveness of balloon dilatation of the prostate and cystoscopy for the treatment of symptomatic benign prostatic hyperplasia. J Urol 1992; 147: 639-644.

9 O'Flynn JD. Early and late management of neuropathic bladder in spinal cord injury patients. J Urol 1978; 120: $726-728$.

10 Santiago JA. Sphincterotomy failure. J Am Paraplegia Soc 1993; 16: $164-168$.

11 Rivas DA, Chancellor MB, Staas WE, Gomella LG. Contact neodymium:yttrium-aluminum-garnet laser ablation of the external sphincter in spinal cord injured men with detrusor sphincter dyssynergia. Urology 1995; 45: 1028 - 1031.

12 Noll F, Sauerwein D, Stöhrer M. Transurethral sphincterotomy in quadriplegic patients: long-term follow-up. Neurourol Urodynam 1995; 14: 351 - 358 .

13 Shaw PJR et al. Permanent external striated sphincter stents in patients with spinal injuries. Br J Urol 1990; 66: 297-302.

14 McInerney PD, Vanner TF, Harris SAB, Stephenson TP. Permanent urethral stents for detrusor sphincter dyssynergia. Br J Urol 1991; 67: 291 - 294.

15 Sauerwein D, Gross AJ, Kutzenberger J, Ringert RH. Wallstents in patients with detrusor-sphincter dyssynergia. J Urol 1995; 154: $495-497$.

16 Chancellor MB et al. Multicentre trial in North America of Urolume urinary sphincter prosthesis. J Urol 1994; 152: 924. 